\title{
COMMENTARY
}

\section{Lorcaserin: Making headway}

\section{Cynthia Gershome*}

\begin{abstract}
Obesity is a global problem which has reached epidemic proportions. Obesity is morbidly associated with metabolic syndrome, type-2 diabetes, cardiovascular disease and increased cancer risk. There is an alarming increase in the incidence of obesity in young children which puts them at a greater risk for developing diseases at a much earlier age. Obesity also imposes a heavy burden on the healthcare system. Lorcaserin, a novel anti-obesity drug, is a selective agonist to $5-\mathrm{HT}_{2 \mathrm{C}}$ receptors thereby reducing food intake and promoting weight loss. Lorcaserin has 15-times and 100-times higher selectivity for the 5- $\mathrm{HT}_{2 \mathrm{C}}$ receptor compared to the $5-\mathrm{HT}_{2 \mathrm{~A}}$ and $5-\mathrm{HT}_{2 \mathrm{~B}}$ receptors, respectively.
\end{abstract}

Keywords: Obesity, novel therapies, lorcaserin, weight loss

\section{Introduction}

Obesity is a global problem which has reached epidemic proportions. Obesity is morbidly associated with metabolic syndrome, type-2 diabetes, cardiovascular disease and increased cancer risk. There is an alarming increase in the incidence of obesity in young children which puts them at a greater risk for developing diseases at a much earlier age. Obesity also imposes a heavy burden on the healthcare system.

Effective intervention for the treatment of obesity is bariatric surgery which involves invasive procedures and carries significant risks. ${ }^{1}$ Reducing calorie intake and leading an active lifestyle through regular exercise although is the best alternative but to achieve significant results takes motivation and commitment over a long time course. Anti-obesity drugs are thus an important intervention as a short term treatment option to patients who are morbidly obese with complications and have restricted abilities to perform physical activity. Current anti-obesity drugs approved by United States Food and Drug Adminstration (USFDA) include phentermine, phentermine/topiramate (Qsymia) and lorcaserin., ${ }^{2,3}$

\section{Obesity and the serotonin system}

Serotonin has a pivotal role in the satiety and control of food intake. Various serotonin/5hydroxytryptamine (5-HT) receptors have been identified and of these, $5-\mathrm{HT}_{2}$ subfamily is a target for many anti-obesity drugs. $5-\mathrm{HT}_{2}$ receptor subfamily includes 5- $\mathrm{HT}_{2 \mathrm{~A}}, 5-\mathrm{HT}_{2 \mathrm{~B}}$ and $5-\mathrm{HT}_{2 \mathrm{C}} .5-\mathrm{HT}_{2 \mathrm{C}}$ receptors are exclusively located in the central nervous system and are involved in the suppression of appetite. This vital role in appetite control makes $5-\mathrm{HT}_{2 \mathrm{C}}$ as a promising anti-obesity target. However, due to highly conserved amino acid sequence between the $5-\mathrm{HT}_{2}$ receptor subfamily, developing highly $5-\mathrm{HT}_{2 \mathrm{C}}$ selective drugs has been a challenging task. Non-selective 5-HT drugs have been shown to reduce body weight but had serious side effects owing to their activation of $5-\mathrm{HT}_{2 \mathrm{~A}}$ and $5-\mathrm{HT}_{2 \mathrm{~B}}$ receptors. ${ }^{4}$

\section{Lorcaserin - the new entrant}

Lorcaserin, a novel anti-obesity drug, was approved by FDA in June $2012^{5}$, marketed by Arena Pharmaceuticals (San Diego, CA) under the trade name Belviq. Chemically lorcaserin is [(1R)-8-chloro1-methyl-2, 3, 4, 5-tetrahydro-1H-3-benzazepine hydrochloride hemihydrate] and is a selective agonist to $5-\mathrm{HT}_{2 \mathrm{C}}$ receptors thereby reducing food intake and promoting weight loss. ${ }^{6,7}$ Lorcaserin has 15 -times and 100-times higher selectivity for the $5-\mathrm{HT}_{2 \mathrm{C}}$ receptor compared to the 5-HT2A and 5- $\mathrm{HT}_{2 \mathrm{~B}}$ receptors, respectively. ${ }^{8}$

Lorcaserin is prescribed along with a lowcalorie diet and regular physical activity for obese patients who have Body Mass Index (BMI) of 30 $\mathrm{kg} / \mathrm{m}^{2}$ or overweight patients with BMI of 27-30 $\mathrm{kg} / \mathrm{m}^{2}$ and also have one of the obesity related conditions such as type- 2 diabetes, high cholesterol or hypertension.

\section{Lorcaserin - the evidence}

Three clinical trials have been published so far evaluating the efficacy and safety of lorcaserin for weight loss in obese population: Behavioral modification and lorcaserin for overweight and obesity management (BLOOM), behavioral modification and 
lorcaserin for overweight and obesity management in patients of diabetes mellitus type 2 (BLOOM DM) and behavioral modification and lorcaserin second study for obesity management (BLOSSOM).9-11 For the BLOOM and BLOSSOM trials, obese or overweight patients were randomized to receive either placebo or lorcaserin $10 \mathrm{mg}$ twice daily for 52 weeks. BLOOM-DM had a similar study design but involved obese patients with type 2 diabetes. These 3 clinical trials demonstrated effective weight loss of $\geq 5-10 \%$ in lorcaserin treated obese patients compared to placebo and also demonstrated a positive outcome on glycated hemoglobin levels, fasting blood glucose, decrease in blood pressure and BMI along with weight loss in obese patients with type- 2 diabetes. Metaanalysis of pooled data from five clinical trials show that lorcaserin caused a modest reduction in the body weight but also caused significant side effects including headache, dizziness, nausea, upper respiratory tract infections and nasopharyngitis. ${ }^{12}$ FDA-defined mitral regurgitation (valvulopathy) side effect also developed in $2.7 \%$ of lorcaserin treated patients compared to $2.3 \%$ in placebo treated patients although statistically not significant. ${ }^{9}$ Other adverse side effects include depression and serotonin syndrome, when lorcaserin is used in combination with other serotonergic drugs such as serotoninnorepinephrine reuptake inhibitors, monoamine oxidase inhibitors, antipsychotics to name a few.

\section{Concluding remarks}

Obesity is a growing health concern across the globe. FDA approval of lorcaserin is a significantly exciting step towards the treatment of obesity. However, large randomised clinical trials in comparison with other anti-obesity drugs are needed to address the benefit to risk ratio for the use of lorcaserin.

\section{Conflict of interest}

Dr. Gershome is an editorial advisory board of member of Diabesity.

\section{References}

1. Fontana MA, Wohlgemuth SD. The surgical treatment of metabolic disease and morbid obesity. Gastroenterol Clin North Am. 2010; 39:125-33. PubMed Full Text
2. Colman E, Golden J, Roberts M, et al. The FDA's assessment of two drugs for chronic weight management. $N$ Engl J Med. 2012; 367:1577-9. PubMed Full Text

3. Mahgerefteh B, Vigue M, Freestone Z, Silver S, Nguyen Q. New drug therapies for the treatment of overweight and obese patients. Am Health Drug Benefits. 2013; 7:423-30. PubMed Full Text

4. Rothman RB, Baumann MH, Savage JE et al. Evidence for possible involvement of $5-\mathrm{HT}$ (2B) receptors in the cardiac valvulopathy associated with fenfluramine and other serotonergic medications. Circulation 2000; 102:2836-41. PubMed Full Text

5. Taylor JR, Dietric E, Powell JG. New and emerging pharmacologic therapies for type 2 diabetes, dyslipidemia and obesity. Clin Ther. 2013; 35:A3-17. PubMed Full Text

6. FDA Center for Drug Evaluation and Research Belviq NDA 022529 drug label, June 27, 2012. www.accessdata.fda.gov/scripts/cder/drugsatfda/index.cf m?fuseaction=Search.DrugDetails. Accessed January 26, 2015

7. Smith BM, Smith JM, Tsai JH et al. Discovery and structure-activity relationship of (1R)-8-chloro-2,3,4,5tetrahydro-1-methyl-1H-3-benzazepine (lorcaserin), a selective serotonin $5-\mathrm{HT} 2 \mathrm{c}$ receptor agonist for the treatment of obesity. J Med Chem. 2008; 51:305-13. PubMed Full Text

8. Thomsen WJ, Grottick AJ, Manzaghi $F$ et al. Lorcaserin, a novel selective human 5hydroxytryptamine2c agonist: in vitro and in vivo pharmacological characterization. J Pharmacol Exp Ther. 2008; 325:577-87. PubMed Full Text

9. Smith SR, Weissman NJ, Anderson $\mathrm{CM}$ et al for the Behavioural Modification and Lorcaserin for Overweight and Obesity Management (BLOOM) study group. Multicenter, Placebo-controlled trial of Lorcaserin for weight management. N Engl J Med. 2010; 363:245-56. PubMed Full Text

10. Fidler MC, Sanchez M, Raether B et al. A one-year randomized trial of lorcaserin for weight loss in obese and overweight adults: the BLOSSOM trial. J Clin Endocrinol Metab. 2011; 96:3067-77. PubMed Full Text

11. O Neil PM, Smith SR, Weissman NJ, et al. Randomized placebo-controlled clinical trial of lorcaserin for weight loss in type 2 diabetes mellitus: the BLOOM-DM study. Obesity 2012; 20:1426-36. PubMed Full Text

12. Chan EW, He Y, chui CSL et al. Efficacy and safety of lorcaserin in obese adults: a meta-anlaysis of 1-year randomized controlled trials (RCTs) and narrative review of short-term RCTs. Obes Rev. 2013; 14:383-92. PubMed Full Text 